\title{
MICROSTRUCTURE-SENSITIVE MODEL FOR PREDICTING SURFACE RESIDUAL STRESS RELAXATION AND REDISTRIBUTION IN A P/M NICKEL-BASE SUPERALLOY
}

\author{
M.E. Burba ${ }^{1}$, D.J. Buchanan ${ }^{2}$, M.J. Caton ${ }^{1}$, R. John ${ }^{1}$, R.A. Brockman ${ }^{2}$ \\ ${ }^{1}$ Air Force Research Laboratory (AFRL/RXCM), Wright-Patterson Air Force Base, OH 45433-7817 \\ ${ }^{2}$ University of Dayton Research Institute, Dayton, OH 45469-0020
}

Keywords: IN100, Residual stress, $\gamma^{\prime}$ precipitates, shot peening, X-ray diffraction

\begin{abstract}
Compressive surface residual stress achieved by mechanical surface treatments (i.e. shot peening, low-plasticity burnishing, laser shock peening, etc.) typically extend component life under fatigue loading. Designers are reluctant to include surface residual stress benefit in design life predictions due to the absence of detailed and accurate models of this behavior and the uncertainty of residual stress profiles that exist both before and after service. Therein lies a need for generalizing current coupled creep-plasticity models to incorporate microstructural features, size distributions, and volume fractions to describe the relaxation mechanisms as integrated computational materials engineering (ICME) practices take hold within the industrial base. The microstructure-sensitive models developed in this research combine the effect $\gamma^{\prime}$ precipitates have on mechanical properties (i.e. yield strength and creep) within a coupled creep-plasticity model framework and baseline residual stress and plastic strain profiles as initial boundary conditions for predicting residual stress relaxation under thermomechanical exposure. Model predictions are validated against shot peened laboratory scale experiments of two different heat treatments of IN100 under service relevant conditions.
\end{abstract}

\section{Introduction}

To take advantage of the beneficial effects of surface residual stress on fatigue and corrosion resistance, a microstructuresensitive model that takes into account the relaxation and redistribution of surface residual stresses is needed. The relaxation of surface residual stress due to elevated temperature fatigue loading is dependent upon both the material microstructure and the applied thermomechanical loading history [1]. Current models do not incorporate microstructure-sensitivity, and provide only semi-empirically, point-driven solutions for a given microstructure specification [2,3]. Detailed characterization of the material is critical when building the foundations for such a model. Likewise, previous studies [4-11] have shown the need for experiments under thermomechanical conditions to be used in validating the residual stress relaxation model.

Nickel-base superalloys can be used at higher fractions of their melting temperatures than nearly any other commercially available alloy [12]. Disk rotors found in the High Pressure (HP) modules of aircraft turbine engines need properties of high yield strength to maximize low cycle fatigue (LCF) resistance, high ultimate strength, high creep resistance, and high damage tolerance to ensure the fatigue crack growth rate is low even when the disk is being stressed under hold times, corrosive environments, and elevated temperatures [12]. $\mathrm{P} / \mathrm{M}$ processed IN100 has high strength and creep resistance at elevated temperatures and therefore meets the required properties needed for a HP disk rotor. IN100 receives its strength and creep resistance from its $\gamma^{\prime}$ coherent $\mathrm{Ni}_{3} \mathrm{Al}$ precipitate structure distributed throughout its austenitic $\gamma \mathrm{Ni}$ solid solution matrix. The $\gamma^{\prime}$ precipitates are both strong and ductile which limits dislocation interaction and movement through the microstructure. Both the $\gamma$ and $\gamma^{\prime}$ precipitates share a face centered cubic (fcc) crystal structure. IN100 is heat treatable, having a $\gamma^{\prime}$ solvus temperature within the range of $1180-1200{ }^{\circ} \mathrm{C}$ [12]. Heat treating materials below the $\gamma^{\prime}$ solvus temperature is referred to as subsolvus whereas heat treating above the solvus temperature is termed supersolvus. This research utilizes two shot peened $\mathrm{P} / \mathrm{M}$ IN100 heat treatments with different microstructures to validate microstructural-sensitive models developed to predict residual stress relaxation exposed to thermomechanical loading.

\section{Microstructural Characterization of IN100}

Grain size distributions were determined using orientation imaging microscopy (OIM) on material surfaces prepared by standard polishing techniques. The OIM data were collected at an electron acceleration voltage of $20 \mathrm{kV}$ with a beam current of 10 $\mathrm{nA}$. The OIM scanned area, step size, and average grain size for each microstructural condition were determined using ASTM E2627-13 [13]. The grain sizes presented were calculated based on the average equivalent diameter determined from the measured grain area with twin boundaries removed from the analysis. The total area scanned to determine the fine-grain average equivalent circular grain diameter was $400 \mathrm{x} 400 \mu \mathrm{m}$ which included over 10,000 grains after edge grains were removed from the dataset. A step size of $0.05 \mu \mathrm{m}$, selected based upon an assumed average grain size of $3 \mu \mathrm{m}$, resulted in 2,825 pixels. The fine-grain material average grain size diameter was calculated to be $3.68 \mu \mathrm{m}$. The minimum grain size was found to be $0.56 \mu \mathrm{m}$ and the maximum grain diameter for the scanned area was $15.79 \mu \mathrm{m}$.

The coarse-grain material required much larger scanned areas to ensure a statistically significant number of grains were represented. The total area scanned was a $1.8 \times 1.4 \mathrm{~mm}$ rectangle that resulted in nearly 6,500 grains sampled. A $0.2 \mu \mathrm{m}$ step size, selected based upon an assumed average grain size of $15 \mu \mathrm{m}$, resulted in 4,415 pixels. The average grain size diameter for the coarse-grain material was found to be $15.3 \mu \mathrm{m}$ with a minimum and maximum grain size diameter of $2.3 \mu \mathrm{m}$ and $119.5 \mu \mathrm{m}$, respectively.

Samples to determine the $\gamma^{\prime}$ precipitates size and distribution within the fine- and coarse-grain material conditions were prepared using standard polishing techniques to a $0.05 \mu \mathrm{m}$ surface finish. Both microstructures were etched using $80 \mathrm{~mL} \mathrm{HCl}, 80$ $\mathrm{mL} \mathrm{HNO}_{3}, 80 \mathrm{~mL} \mathrm{H} \mathrm{H}_{2} \mathrm{O}, 2.4 \mathrm{~g}$ Molybdic Acid [14] to preferentially remove the $\gamma^{\prime}$ precipitates from the $\gamma$ matrix and determine size and area fraction of the precipitates. Micrographs were acquired using an ultra-high resolution imaging technique in 
the scanning electron microscope at magnifications and resolutions to ensure the voids remaining from the removal of the $\gamma^{\prime}$ precipitates allowed for the tertiary $\gamma^{\prime}$ precipitates $(\sim 25 \mathrm{~nm})$ to be clearly resolved. Micrograph magnifications were chosen to yield approximately 100 precipitates of a given distribution per field of view, with the one exception of the fine-grain tertiary $\gamma^{\prime}$ due to their small area fraction. Ten random fields of view were selected to be imaged per each precipitate distribution in order to achieve the most representative size and area fraction of the $\gamma^{\prime}$ precipitates. Figure 1 depicts subset examples of both microstructures at various magnification levels to quantify the size distributions of the $\gamma^{\prime}$ precipitates. Image processing included highlighting the precipitate voids and inputting the segregated images into a script file to calculate the equivalent diameter and area fraction.

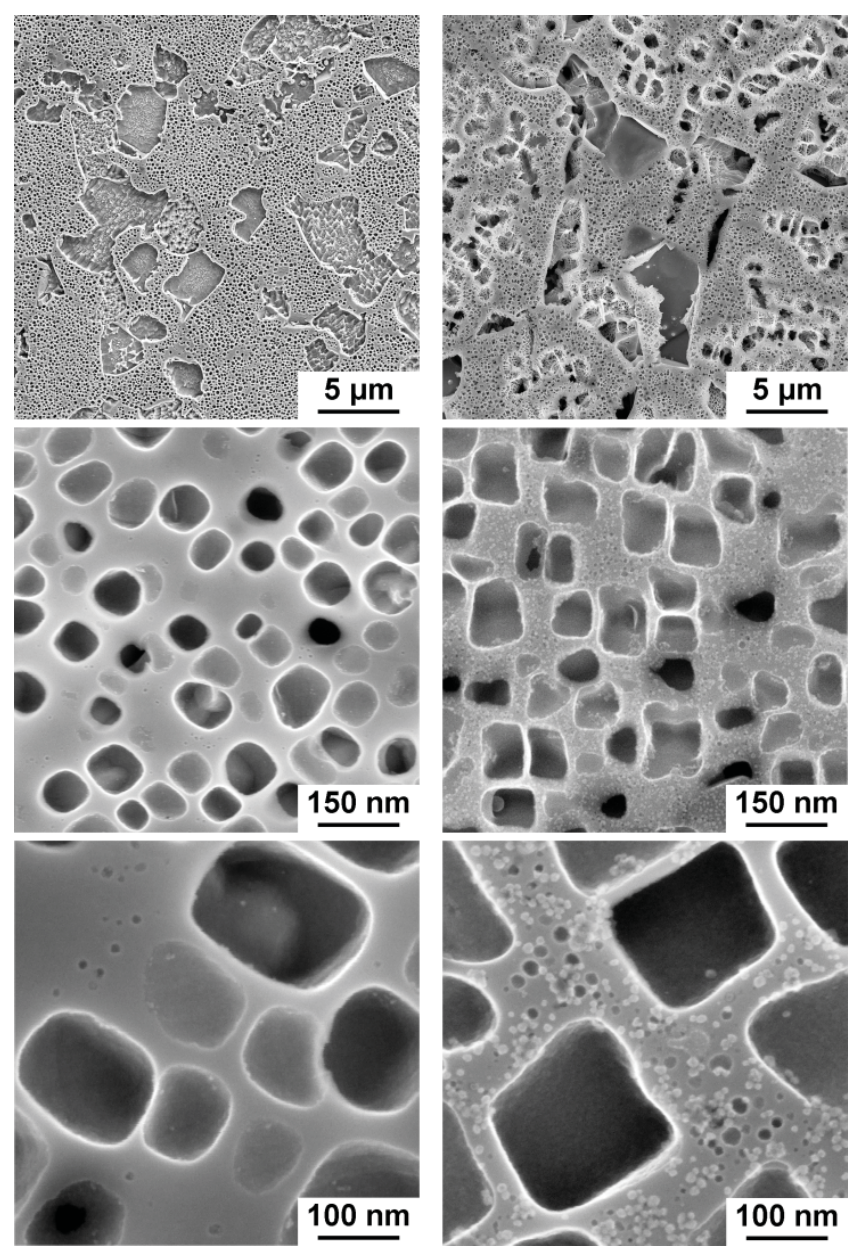

Figure 1. Micrographs demonstrating the size and image quality of the etched images used to measure the $\gamma^{\prime}$ precipitates. The left column represented the fine-grain material and the right column is the coarse-grain.

The etched images for the fine-grain material exhibited three size distributions of $\gamma^{\prime}$. The largest $\gamma^{\prime}$ precipitates are primary $\gamma^{\prime}(2.00$ $\mu \mathrm{m})$ which remain undissolved during the solution treatment when the solution treatment temperature is less than the $\gamma^{\prime}$ solvus temperature. The next size distribution is termed secondary $\gamma^{\prime}$ $(0.12 \mu \mathrm{m})$ and the smallest size distribution is tertiary $\gamma^{\prime}(0.011$ $\mu \mathrm{m})$. The coarse-grain material was heat treated above the $\gamma^{\prime}$ solvus temperature, thus removing all primary $\gamma^{\prime}$. There were four size distributions of $\gamma^{\prime}$ found in the coarse-grain condition: grain boundary $\gamma^{\prime}(2.27 \mu \mathrm{m})$, secondary $1 \gamma^{\prime}(1.01 \mu \mathrm{m})$, secondary $2 \gamma^{\prime}$ $(0.16 \mu \mathrm{m})$, and tertiary $\gamma^{\prime}(0.012 \mu \mathrm{m})$. All precipitate sizes indicated were calculated based on the average equivalent diameter determined from the precipitate area. The fine- and coarse-grain material have different precipitate size distributions due to dissimilar solution treatment cycles and corresponding cooling rates following the solution treatment [15]. $\gamma^{\prime}$ precipitate size and area fraction are shown in Table 1 along with the results from the grain size quantification.

Table I. Quantification of Grain Size and $\gamma^{\prime}$ Precipitate Structure

\begin{tabular}{|l|c|c|c|}
\hline \multirow{2}{*}{ Phase } & \multicolumn{3}{|c|}{ Fine-Grain IN100 } \\
\cline { 2 - 4 } & $\mathbf{V}_{\mathbf{f}}$ & Size $(\boldsymbol{\mu m})$ & Observations \\
\hline $\boldsymbol{\gamma}$ matrix & 0.34 & 3.68 & 10,260 \\
\hline Primary $\boldsymbol{\gamma}^{\prime}$ & 0.31 & 2.00 & 1,123 \\
\hline Secondary $\boldsymbol{\gamma}^{\boldsymbol{\prime}}$ & 0.35 & 0.12 & 951 \\
\hline Tertiary $\boldsymbol{\gamma}^{\boldsymbol{\prime}}$ & 0.004 & 0.011 & 391 \\
\hline \multirow{3}{*}{ Phase } & \multicolumn{3}{|c|}{ Coarse-Grain IN100 } \\
\cline { 2 - 4 } $\boldsymbol{\gamma}$ matrix & $\mathbf{V}_{\mathbf{f}}$ & Size $(\boldsymbol{\mu m})$ & Observations \\
\hline Grain Boundary $\boldsymbol{\gamma}^{\prime}$ & 0.47 & 15.28 & 6,419 \\
\hline Secondary $\mathbf{1} \boldsymbol{\gamma}^{\prime}$ & 0.07 & 2.27 & 2,242 \\
\hline Secondary $\mathbf{2} \boldsymbol{\gamma}^{\prime}$ & 0.16 & 1.01 & 1,070 \\
\hline Tertiary $\boldsymbol{\gamma}^{\boldsymbol{\prime}}$ & 0.09 & 0.16 & 2,113 \\
\hline
\end{tabular}

Common research practice is to determine the $\gamma^{\prime}$ precipitate volume fractions by measuring the larger precipitate distributions, using similar imaging techniques as shown in this research, and calculating the tertiary $\gamma^{\prime}$ volume fraction as the remainder of the total $\gamma^{\prime}$ precipitate volume fraction. The total volume fraction calculations are typically achieved using thermodynamic modeling software. One aim of this study was to measure the size and volume fraction for each precipitate distribution using the etched and imaging technique due to the major improvements to scanning electron microscopy (SEM) and the simple nature of the technique, which could be adopted by most research facilities. Total volume fractions measured for the fine-grain material were found to be 0.66 and 0.53 for the coarse-grain material. These total volume fraction values are close to the 0.60 total volume fraction calculated for this alloy [16] and were used for the development of the models.

Tensile experiments were performed on the fine- and coarse-grain material at room and elevated temperature $\left(650{ }^{\circ} \mathrm{C}\right)$ to further characterize the material for model development. The specimen geometry was a cylindrical gage-section dogbone with a nominal gage diameter of $5 \mathrm{~mm}$ and a nominal gage length of $15.2 \mathrm{~mm}$ as described in [17]. The gage section surface finish was low stress ground (LSG). The tensile tests were conducted using a uniaxial test frame under strain rate control $(0.001 / \mathrm{s})$. Extensometers were used during testing to measure displacement on all experiments described. Elevated temperature testing was achieved using a resistance furnace. A temperature profile study was performed to determine the temperature profile across the gage section and extensometer gage length. The temperature profile was used to establish the temperature control point outside of the reduced gage section. 
The true stress verses true strain profiles for both microstructures are shown in Figure 2 and Figure 3 at room and elevated temperature, respectively. During the room temperature tensile test, the fine-grain material demonstrated an upper yield point prior to the onset of plastic deformation, potentially due to the Cottrell locking phenomenon. This was not seen in the coarsegrain material at room temperature, nor in either material at 650 ${ }^{\circ} \mathrm{C}$. The Young's modulus at room temperature was determined to be $220 \mathrm{GPa}$ for both microstructures. Similarly at $650{ }^{\circ} \mathrm{C}$, both microstructures demonstrated the same Young's modulus of 182 $\mathrm{GPa}$. The $0.2 \%$ offset yield strength for the fine-grain material at room temperature was determined to be $1075 \mathrm{MPa}$ and slightly less for the coarse-grain material, measuring $920 \mathrm{MPa}$. Tensile tests at $650{ }^{\circ} \mathrm{C}$ showed that the fine-grain material had a slight drop in yield strength measuring $1055 \mathrm{MPa}$ while the coarse-grain continued to have $920 \mathrm{MPa}$ yield strength. These results are consistent with data reported for fine- and coarse-grain IN100 by Kozar et al. [18].

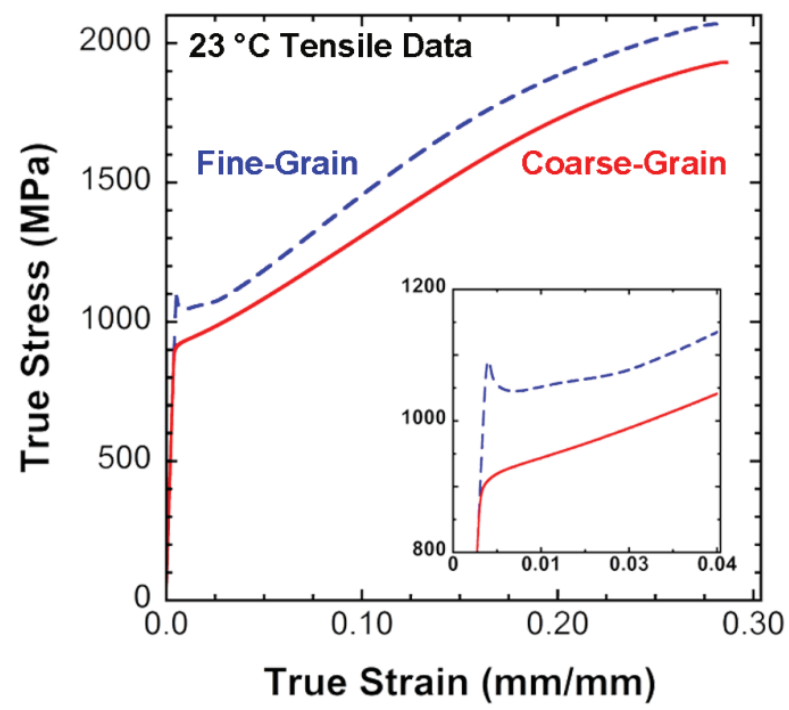

Figure 2. Monotonic true stress versus true strain curves at room temperature with inset highlighting behavior at yield.

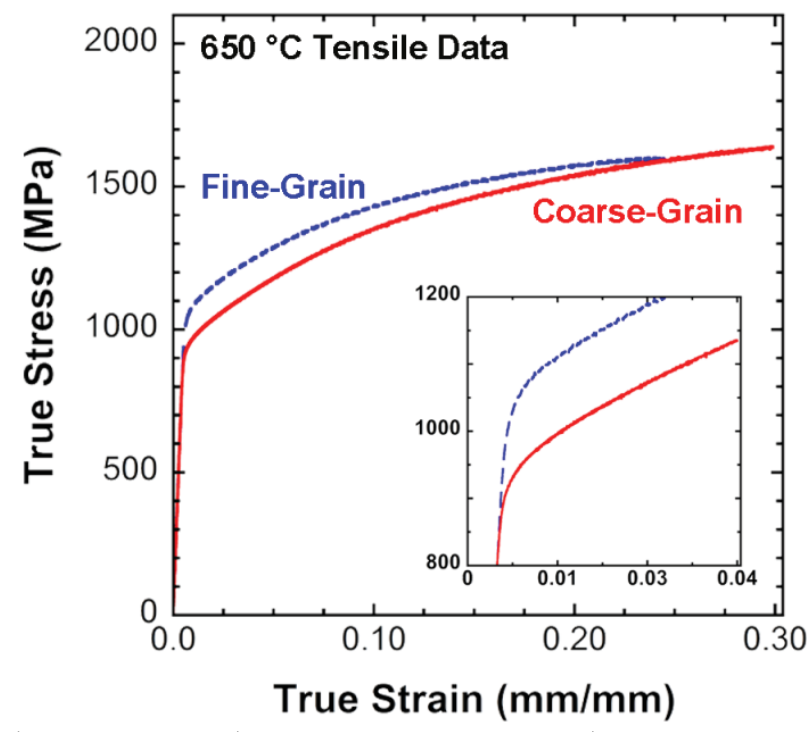

Figure 3. Monotonic true stress versus true strain curves at $650{ }^{\circ} \mathrm{C}$ with inset highlighting behavior at yield.

\section{Prestrain Effect on Creep Behavior in IN100}

Development of the coupled creep-plasticity model by Buchanan et al. [2] indicates that a few parameters must still be optimized for each microstructure based on the effect of prior room temperature prestrain before creep exposure. The room temperature prestrain can be related to the amount of cold work (plastic deformation) that occurs at the surface of the material during shot peening. Incorporating the effects of prestrain on creep allows for the coupled creep-plasticity model to be developed and optimized using unpeened experimental data. The model can be validated using shot peened experimental results that are completely unbiased by the shot peened residual stress relaxation experiments.

Prestrain creep experiments were completed using the same specimen geometry, loading frame, and elevated temperature furnace setup described for the monotonic tensile experiments. The amount of displacement required to reach a specified prestrain percentage was calculated using the room temperature tensile curve. The prestrain was applied to each specimen by loading in strain control at a rate of $0.001 / \mathrm{s}$ and a displacement limit to initialize unloading. Following application of the prestrain, the specimen areas were remeasured for creep loading determination. Creep experiments were conducted with the same setup described above with one exception. The experiments were run in load control rather than strain control to confirm each creep experiment was performed at the appropriate stress level. The loading rate was designed to match as closely to the $0.001 / \mathrm{s}$ strain rate ramp to load.

The effect of different levels of room temperature prestrain on creep for the fine-grain material is shown in Figure 4 for 1100 $\mathrm{MPa}, 650^{\circ} \mathrm{C}$. The square data points represent no plastic prestrain before exposure to creep. The compressive prestrain effect, represented by the circle data points, show the compressive prestrain has a negative effect on creep resistance when compared to no prestrain before creep. Increasing the amount of prestrain results in a nonlinear increase in creep resistances for the conditions shown. It can also be observed from the results that the effect of prestrain saturates in the neighborhood of $12 \%$ prestrain.

Similar effects of prestrain on creep are shown for the coarsegrain material at $1000 \mathrm{MPa}$ in Figure 5. The main differences for the coarse-grain can be seen for the prestrain amounts surrounding no prestrain. The compressive prestrain has a slightly higher creep resistance than no prestrain at this stress level. The $-0.5 \%$, $0 \%$ and $1 \%$ prestrain amounts have nearly no effect of prestrain which was not the case for the fine-grain material. The same effect of prestrain saturation exists near $15 \%$ prestrain as it did for the fine-grain material.

The time to $0.5 \%$ creep strain for different combinations of stresses and prestrain levels are shown in Table II for the fine- and coarse-grain IN100. Normalizing the loading stress to the yield strength of the material has also been introduced to fully compare the differences between the two microstructures. Focusing on the same stress level (1000 MPa) for both microstructures, it can be remarked that the fine-grain has longer times to $0.5 \%$ than the coarse-grain for all prestrain below $5 \%$. The trend changes with the coarse-grain material demonstrating more creep resistance when $5 \%$ prestrain is imposed. Although the coarse-grain 
material was expected to have increased creep resistance compared to the fine-grain material, this is not completely true for all levels of stress. Creep studies performed on another nickelbase superalloy (LSHR) show similar results of the fine-grain outperforming the coarse-grain when creep experiments are tested near the yield strength of the material [19]. Another explanation of this trend is that the fine-grain material is being tested below its yield strength and the coarse-grain nearly $10 \%$ higher than its yield strength. Testing the fine-grain material at $1000 \mathrm{MPa}$ results in a similar ratio of yield stress as the coarse-grain tested at 900 MPa. As shown in Table II, the coarse-grain material has a much higher resistance to creep when comparing the results at these two conditions for all tested prestrains. The symbol (-) represented in Table II denotes no experiment for that condition.

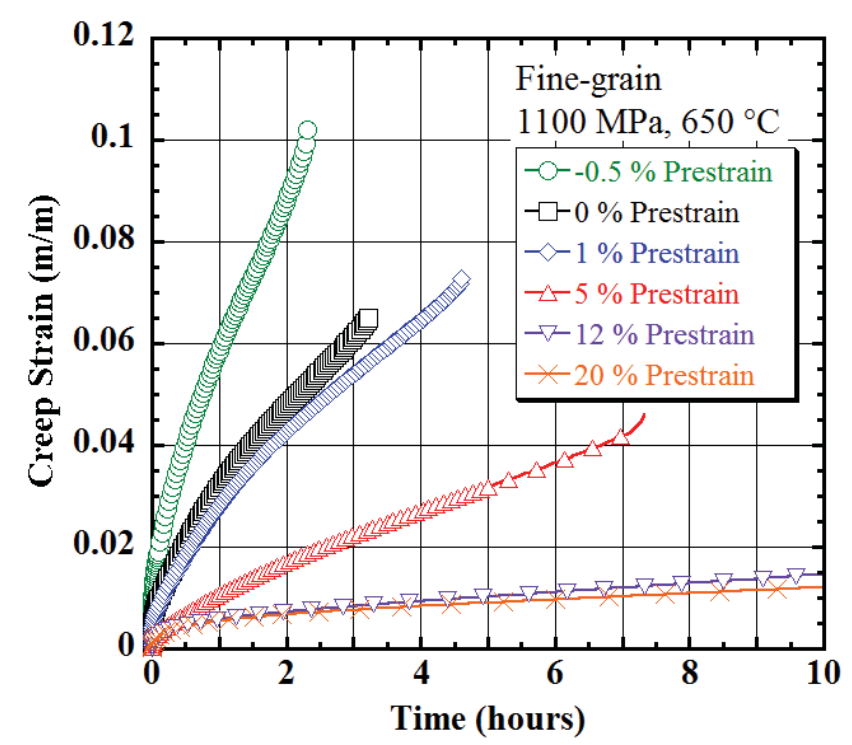

Figure 4. Creep strain versus time curves for fine-grain material tested at $1100 \mathrm{MPa}$ and $650{ }^{\circ} \mathrm{C}$ at varying room temperature prestrain levels.

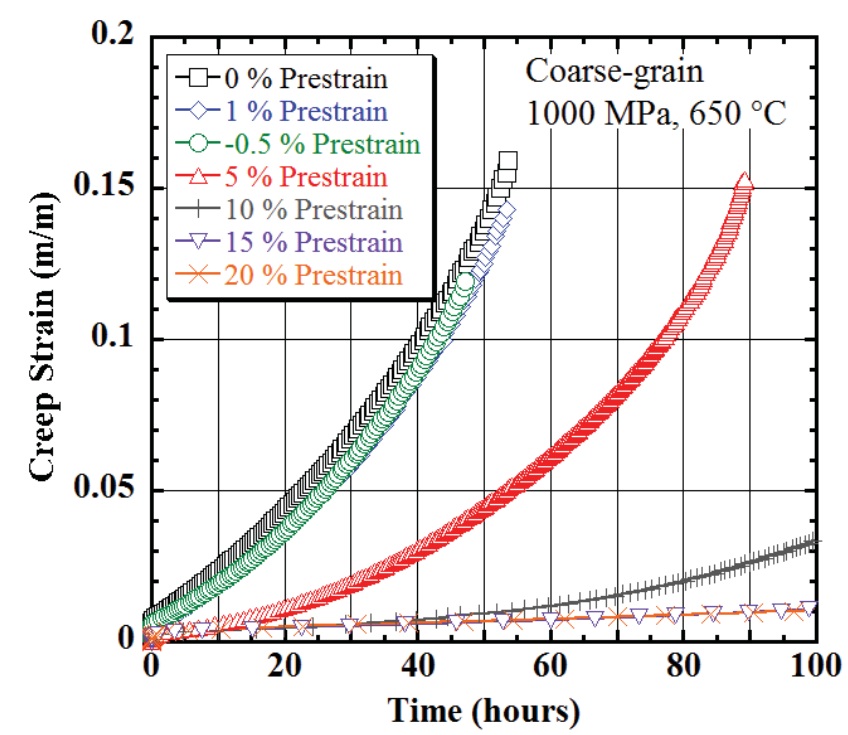

Figure 5. Creep strain versus time curves for coarse-grain material tested at $1000 \mathrm{MPa}$ and $650{ }^{\circ} \mathrm{C}$ at varying room temperature prestrain levels.
Table II. Time to $0.5 \%$ Creep in hours

\begin{tabular}{|l|c|c|c|c|c|c|}
\hline \multicolumn{1}{|c|}{$\mathbf{6 5 0}^{\circ} \mathbf{C}$} & \multicolumn{3}{|c|}{ Fine-Grain } & \multicolumn{2}{c|}{ Coarse-Grain } \\
\hline Creep Stress (MPa) & $\mathbf{9 4 0}$ & $\mathbf{1 0 0 0}$ & $\mathbf{1 0 5 0}$ & $\mathbf{1 1 0 0}$ & $\mathbf{9 0 0}$ & $\mathbf{1 0 0 0}$ \\
\hline Stress Ratio of YS & 0.89 & 0.95 & 1.00 & 1.04 & 0.98 & 1.09 \\
\hline $\mathbf{- 0 . 5} \%$ Prestrain & 8.68 & 0.47 & 0.06 & 0.00 & 26.84 & 0.03 \\
\hline $\mathbf{0} \%$ Prestrain & 40.16 & 3.70 & 0.13 & 0.01 & 24.95 & 0.01 \\
\hline $\mathbf{1} \%$ Prestrain & - & 1.53 & 0.14 & 0.02 & 59.87 & 0.10 \\
\hline $\mathbf{5 \%}$ Prestrain & 19.45 & 1.41 & 0.61 & 0.29 & 120.99 & 7.80 \\
\hline $\mathbf{1 0} \%$ Prestrain & 27.96 & - & - & - & - & 22.53 \\
\hline $\mathbf{1 2} \%$ Prestrain & - & - & - & 0.63 & - & - \\
\hline $\mathbf{1 5 \%}$ Prestrain & - & - & - & - & - & 26.36 \\
\hline $\mathbf{2 0} \%$ Prestrain & - & - & - & 0.74 & - & 20.50 \\
\hline
\end{tabular}

Determining the parameters required to describe the coupled creep-plasticity response of each microstructure requires knowledge of any plastic deformation prior to reaching the desired creep stress. Plastic deformation does not always occur at all levels of stress or prestrain, but is essential to the model development if it does occur. The template of plotting the total strain on the abscissa and the total strain rate on the ordinate, both in log scale, has been adopted in order to characterize the entire strain history of each experiment. Figure 6 depicts the fine-grain material behavior plotted using this template. The fine-grain material was subjected to $1000 \mathrm{MPa}$ which is just below the yield strength of the material. The experimental results are plotted as the filled circles and the open diamonds are the model prediction. The elastic loading strain rate was $\sim 0.001 / \mathrm{s}$ as described in the experimental setup. There is some plastic strain accumulation just before reaching $1000 \mathrm{MPa}$ but the model prediction is able to capture the entire profile well after optimizing the parameter for a subset of all the experimental conditions. Details of the model and optimized parameters will be discussed in later sections.

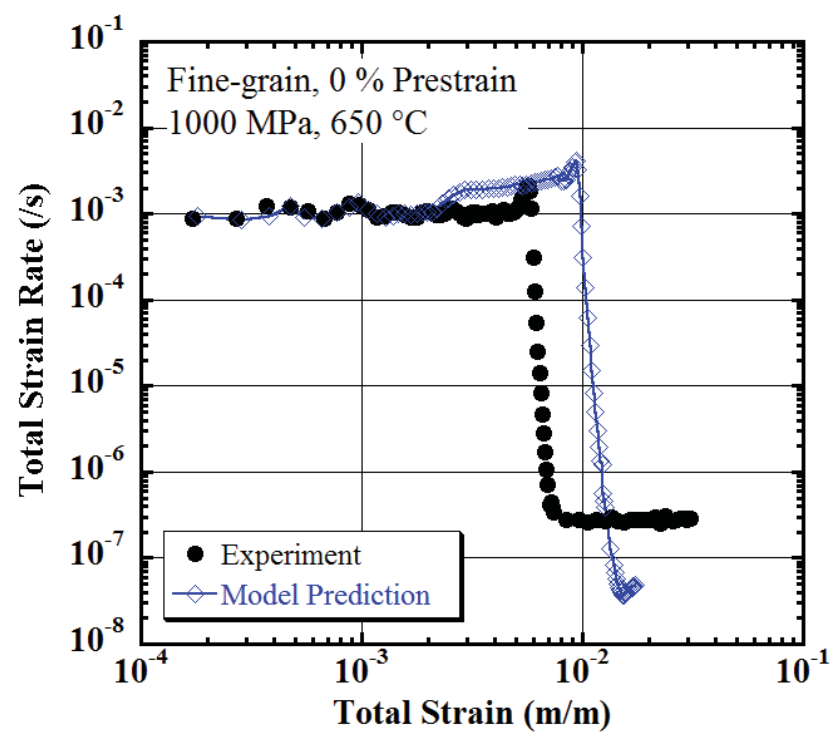

Figure 6. Total strain rate versus total strain for fine-grain IN100 at $\sigma \_\max =1000 \mathrm{MPa}, 0 \% \mathrm{RT}$ prestrain, and $650{ }^{\circ} \mathrm{C}$.

The coarse-grain results in Figure 7 correspond to baseline test at $1000 \mathrm{MPa}$ with no prestrain. The experimental data is depicted by the filled circles and the model prediction by the open squares. Similar to the fine-grain material, the coarse-grain shows a loading strain rate of $\sim 0.001 / \mathrm{s}$. The coarse-grain material accumulated more plastic strain up to the creep load due to the lower yield strength of the coarse-grain material. The model 
prediction seems to capture the experiment response after optimizing the coupled creep-plasticity parameters over a subset of the experiments.

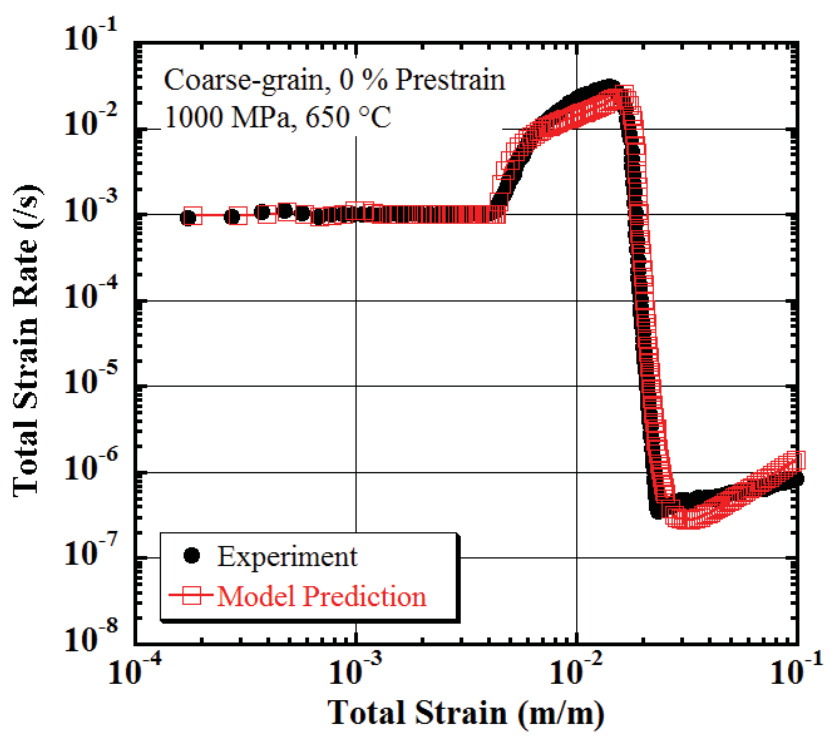

Figure 7. Total strain rate versus total strain for coarse-grain $\mathrm{IN} 100$ at $\sigma \_\max =1000 \mathrm{MPa},-0.5 \% \mathrm{RT}$ prestrain, and $650^{\circ} \mathrm{C}$.

\section{Coupled Creep-Plasticity Model including Microstructure}

The objective of this research was to improve on the coupled creep-plasticity model developed by Buchanan et al. [2] to be more physics based and less empirical. Buchanan et al.'s model consists of a rate-independent plasticity model which is then coupled with a strain hardening creep model by the plastic strain rate and yield surface size as shown by

$$
\dot{\bar{\varepsilon}}^{c}=\dot{\varepsilon}_{0}\left(1+\bar{\varepsilon}^{i n}\right) \sinh \left[\frac{\sigma-\alpha}{\sigma_{\kappa} \kappa}\right]
$$

where $\dot{\bar{\varepsilon}}^{c}$ is the effective creep strain rate, $\dot{\varepsilon}_{0}$ is the creep strain rate parameter, $\bar{\varepsilon}^{i n}$ is the effective stain rate parameter which is an additive solution of both the plastic and creep strain rates, $\sigma$ is the loading stress, $\alpha$ is the total backstress which is a summation of the creep backstress evolution and plastic hardening, $\sigma_{\kappa}$ is the normalized stress parameter, and $\kappa$ is the size of the yield surface. Buchanan et al.'s model required an optimization routine to estimate seven parameters in order to describe the creep behavior. Physics based approaches to modelling the creep behavior of superalloys incorporating intragranular microstructural features have been studied [20-24]. Dyson's creep model [20] takes the following form

$$
\dot{\varepsilon}^{c}=\dot{\varepsilon}_{0}\left(1+D_{d}\right) \sinh \left[\frac{\sigma(1-H)}{\sigma_{0}}\right]
$$

where $D_{d}$ is a damage parameter proportional to the creep rate, $\mathrm{H}$ is a dimensionless hardening parameter, and $\sigma_{0}$ is the stress constant. The stress constant is calculated from the Taylor factor $\bar{M}$, Boltzmann's constant $k$, the temperature $T(\mathrm{~K})$, Burgers vector $b$, and the inter-particle distance $\lambda$.

$$
\sigma_{0}=\frac{\bar{M} k T}{b^{2} \lambda}
$$

The microstructure-sensitive coupled creep-plasticity model developed combines aspects of the mechanical creep strain modeling approach (equation 1) with the physics-based creep strain modeling approach (equation 2) into one cohesive model with the following formulation:

$$
\dot{\bar{\varepsilon}}^{c}=\dot{\varepsilon}_{0}\left(1+\bar{\varepsilon}^{i n}\right) \sinh \left[\frac{\sigma-\alpha}{\sigma_{0}}\right]
$$

$D_{d}$ was replaced by $\bar{\varepsilon}^{i n}$ to include the plastic deformation rate as well as the creep deformation rate. $(1-H)$ was replaced solely by $\alpha$ to continue to incorporate the hardening, but to also include the creep backstress. The creep strain rate parameter was found empirically in [2] where it is calculated based on microstructural parameters as in [24] and shown in equation 5.

$$
\dot{\varepsilon}_{0}=1.6 D C_{j} \bar{M}^{-1} \rho_{m} V_{f}\left(1-V_{f}\right)\left[\left(\pi / 4 V_{f}\right)^{1 / 2}-1\right]
$$

$D$ is the coefficient of diffusion, $C_{j}$ is the dislocation jog density, $\rho_{m}$ is the mobile dislocation density, and $V_{f}$ is the total intragranular $\gamma^{\prime}$ precipitate volume fraction. The coefficient of diffusion is modeled with Arrhenius's equation

$$
D=D_{0} \exp \left(\frac{-Q}{R T}\right)
$$

where $D_{0}$ is the pre-exponential diffusivity, $\mathrm{Q}$ is the activation energy, and R is the gas constant. Values for all the IN100 material constants can found in Table III.

Coakley et al. [24] developed a physics based creep model for a supersolvus Nimonic 115 (Ni115) with a bimodal distribution of $\gamma^{\prime}$ precipitates. The same assumptions and calculations did not apply to two IN100 microstructures due to the tri and quadmodal distributions and thus the more simplistic model was used. Additionally, Coakley et al. assumed that the creep resistance was dominated by only the tertiary $\gamma^{\prime}$ precipitates. This assumption was not used for this study since the fine-grain material has nearly no tertiary $\gamma^{\prime}$ and yet exhibits resistance to creep. This study assumed that all intragranular $\gamma^{\prime}$ (secondary and tertiary) precipitates contributed to the overall creep strength of the material and the stress constant was calculated for each distribution and combined additively. The coupled creepplasticity model framework does allow for higher order precipitate distribution models to be implemented in the future following their development.

Table III. Microstructural Parameters of the IN100 Creep Model

\begin{tabular}{lr}
\hline Taylor factor $\bar{M}$ & 3.0 \\
Pre-exponential diffusivity $D_{0}\left(\mathrm{~m}^{2} \mathrm{~s}^{-1}\right)$ & $1.4 \times 10^{-4}$ \\
Jog Density C $_{\mathrm{i}}$ & 1.0 \\
Mobile dislocation density $\rho_{\mathrm{m}}\left(\mathrm{m}^{-2}\right)$ & $10^{10}$ \\
Boltzmann's constant $k\left(\mathrm{~J} \mathrm{~K}^{-1}\right)$ & $1.38 \times 10^{-23}$ \\
Burgers vector $b(\AA)$ & 2.54 \\
Gas constant $\mathrm{R}\left(\mathrm{J} \mathrm{mol}^{-1} \mathrm{~K}^{-1}\right)$ & 8.314 \\
Activation energy Q $\left(\mathrm{J} \mathrm{mol}^{-1}\right)$ & 310000 \\
Temperature $\mathrm{T}(\mathrm{K})$ & 923.15 \\
\hline
\end{tabular}

Coakley et al. calculated of the inter-particle spacing for secondary $\gamma^{\prime}$ precipitates using the volume fraction as measured. Contrarily, an effective volume fraction should be calculated for 
the tertiary $\gamma^{\prime}$ precipitate distribution to determine inter-particle spacing without the influence of the larger precipitates. The effective volume fraction calculated for the tertiary $\gamma^{\prime}$ is shown by

$$
V_{f, \text { effective }}=\left[V_{f, \text { tertiary }} /\left(1-V_{f, \text { secondary }}\right)\right] * 100
$$

Lastly, the equation for calculating the inter-particle spacing for all the intragranular $\gamma^{\prime}$ precipitate distributions is as follows where $r$ is the average radius of the precipitate distribution.

$$
\lambda=1.6 r\left(\sqrt{\frac{\pi}{4 V_{f}}}-1\right)
$$

The four remaining empirical parameters are $C_{c}, \gamma_{c}, \mathrm{M}$, and $\mathrm{N}$. Both $C_{c}$ and $\gamma_{c}$ are found within the calculation for the backstress and $\mathrm{M}$ and $\mathrm{N}$ are coefficients required for the effective strain rate parameter calculation. Further details can be found in [2]. All of the parameters required for the creep calculation are given in Table IV for each microstructure.

The fine-grain material has a lower stress constant which is consistent with the fine-grain material having a lower creep resistance. Conversely, the fine-grain material has an order of magnitude lower creep strain rate parameter value when compared to the coarse-grain. This is an area that could need additional investigation in the future and could be an effect of the assumption of using the total volume fraction to calculate the creep strain rate.

Table IV. Coupled Creep-Plasticity Model Parameters for Fineand Coarse-Grain Microstructures

\section{Fine-grain}

Strain hardening coefficient $K(\mathrm{MPa})$

1326.57

Strain hardening exponent $n$

Creep strain rate parameter $\dot{\varepsilon}_{0}\left(\mathrm{~s}^{-1}\right)$

Stress constant $\sigma_{0}(\mathrm{MPa})$

Creep backstress hardening parameter $\mathrm{C}_{\mathrm{c}}(\mathrm{MPa})$

Creep backstress recall parameters $\gamma_{c}$

Creep dislocation multiplication parameter $\mathrm{N}$

Plastic dislocation multiplication parameter $\mathrm{M}$

\section{Coarse-grain}

Strain hardening coefficient $K(\mathrm{MPa})$

Strain hardening exponent $n$

Creep strain rate parameter $\dot{\varepsilon}_{0}\left(\mathrm{~s}^{-1}\right)$

Stress constant $\sigma_{0}(\mathrm{MPa})$

Creep backstress hardening parameter $\mathrm{C}_{\mathrm{c}}(\mathrm{MPa})$

Creep backstress recall parameters $\gamma_{c}$

Creep dislocation multiplication parameter $\mathrm{N}$

Plastic dislocation multiplication parameter $\mathrm{M}$

\section{Shot Peen Thermomechanical Model Validation}

To predict the residual stress relaxation profile under thermomechanical loading, the initial residual stress and plastic strain imparted on the material during shot peening must be accurately defined within the finite element model's input file. The shot peening intensity was $6 \mathrm{~A}(-0 /+2)$ with a $125 \%$ coverage. Almen strips were collected before and after peening the samples to ensure that the peening conditions did not change over time. This must be considered to attempt to minimize the shot peening variability that is inherent to shot peening. Multiple baseline specimens were measured for each microstructural condition to account for the variability in both the peening and the residual stress measurements. A total of six baseline measurements were collected for the fine-grain material and five for the coarse-grain material. The residual stress profiles were measuring with x-ray diffraction (XRD).

XRD uses X-ray peak broadening to measure the amount of stress that remains at a given depth. Material is incrementally removed using electropolishing techniques to create the residual stress profile. The Young's modulus, Poisson's ratio and $\mathrm{x}$-ray elastic constant (XEC) are required input parameters to relate the peak broadening to the amount of stress. Additional details can be found in [25]. The XEC is measured experimentally from a test coupon loaded elastically in a four-point bending test configuration and is explained in detail in ASTM E1426-14 [26]. The knowledge of the XEC is critical as it changes the magnitude of the residual stress profile. If the XEC is assumed or improperly measured, the baseline profile required for the finite element model will be erroneous. This study performed a round robin study on the XEC to make the model inputs as close to actuality as possible. The same two specimens, one fine-grain and the other coarse-grain, were sent to three separate vendors for measurement. The material data provided to each vendor was the same. All three vendors required Young's modulus, Poisson's ratio, and ultimate yield strength. The ultimate yield strength provided to the vendors was $75 \%$ of the total strength to guarantee that the specimens were not plastically deformed and could be sent to the others without any deformation changing the materials response. The results of the study are shown in Table V. It can be assumed that the XEC for the fine-grain and coarse-grain material should be nearly identical since they have the same room temperature elastic modulus. As shown in the table, vendor 1 had significantly different measurement results when compared to vendors 2 and 3 . Due to this finding, the XEC for both microstructures was calculated as average of the measured values from vendors 2 and 3 with the measurement from vendor 1 being discarded. The XEC was $181.2 \mathrm{GPa}$ for the fine grain material and $169.8 \mathrm{GPa}$ for the coarse-grain material.

Table V. X-ray Elastic Constants Measurements

\begin{tabular}{lclc}
\hline Fine-grain & $\mathrm{GPa}$ & Coarse-grain & $\mathrm{GPa}$ \\
Vendor 1 & 132.8 & Vendor 1 & 201.6 \\
Vendor 2 & 172.6 & Vendor 2 & 163.4 \\
Vendor 3 & 189.7 & Vendor 3 & 176.2 \\
\hline
\end{tabular}

Furthermore, to make every attempt to ensure the residual stress profiles were captured to the best of the ability, two vendors were used for the XRD measurements and a separate residual stress measurement technique was used that does not require the XEC. Prism $^{\circledR}[27,28]$ is a relatively new surface residual stress measurement technique, similar to traditional hole drill methods, with hole drilling being combined with digital imaging and electronic speckle pattern interferometry (ESPI) which removes the need for special sample surface preparation and application of strain gages. The drilling is also on a much smaller scale than traditionally used with the hole diameter of $0.8 \mathrm{~mm}$ and depth increments as small as $10 \mu \mathrm{m}$. Prism measurements require prior knowledge of the Young's modulus and Poisson's ratio to compute the residual stress and strain from the displacement measurements.

Prism is a registered trademark of American Stress Technologies, www.astresstech.com. 
The geometry used for the thermomechanical validation experiments was similar to the tensile and prestrain creep geometry except the gauge section was chosen to be square as opposed to cylindrical. The square gage section had a $5 \mathrm{~mm}$ width and a $12 \mathrm{~mm}$ length. The square gage section was chosen over the cylindrical for ease of XRD measurements. Thermomechanical experiments were conducted with the same test frame, in load control, and with displacement data captured as described previously. Cyclic experiments had testing parameters of $\mathrm{R}=0.05$, a frequency of $0.333 \mathrm{~Hz}$ and a sinusoidal loading profile.

The geometry for the finite element model used to predict the residual stress relaxation was a rectangular slug removed from the center of the square gage section with a shot peened surface area of $100 \mu \mathrm{m} \times 100 \mu \mathrm{m}$ as shown in Figure 8. Depth of the mesh geometry was $2500 \mu \mathrm{m}$ to model from the peened surface to the midpoint depth. Boundary conditions were created to simulate the geometry being surrounded by material with the exception of the shot peened surface.
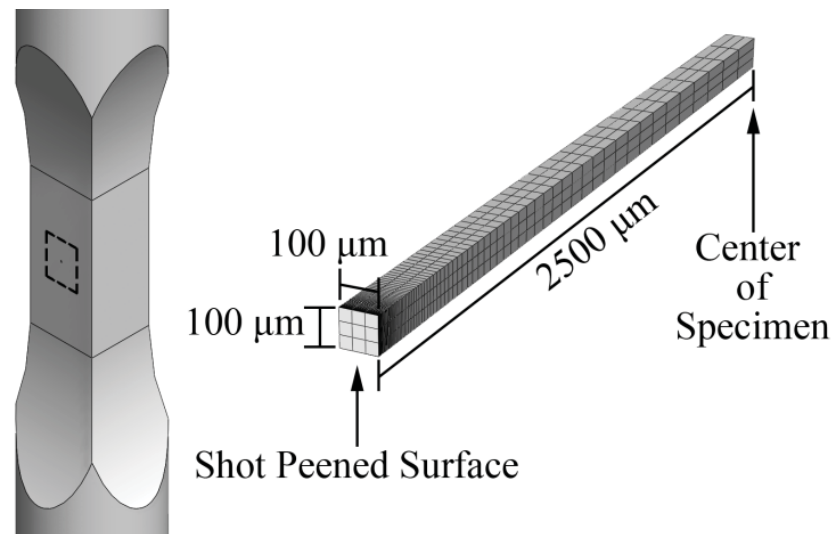

Figure 8. Schematic of dogbone specimen gage section and finite element geometry.

Results from the thermomechanical exposure, baseline residual stress profile, and model prediction for the coarse-grain material are shown in Figure 9 and Figure 10 for different loading histories. The baseline profile consists of 5 separate samples measured using XRD. The fit shown is a least squares fit to the data using Equation 9 [29] where $\left(\sigma_{\text {sur }}\right)$ is the surface residual stress, $\left(\sigma_{\text {int }}\right)$ is the compensatory internal tensile residual stress and $(\mathrm{C} 1, \mathrm{C} 2)$ are fitting parameters. Fitting the parameters to the data required the minimization of the squared residuals, subject to constraints to ensure stress equilibrium is satisfied throughout the geometry. The error bars in both Figures 9 and 10 represent the one standard deviation from the data for the baseline profile.

$$
\sigma_{R S}(x)=\left[\left(\sigma_{\text {sur }}-\sigma_{\text {int }}\right)+C_{1} x\right] \exp \left(-C_{2} x\right)+\sigma_{\text {int }}
$$

Figure 9 shows the coarse-grain relaxation for testing for a single loading cycle to $900 \mathrm{MPa}$ at $650{ }^{\circ} \mathrm{C}$. The peak compressive residual stress for the baseline condition (circle data points) is near $-1100 \mathrm{MPa}$ and relaxes to approximately $-650 \mathrm{MPa}$ after thermomechanical exposure (square data points). The experimental data was collected from Buchanan et al. [2] with the error bars representing $3 \sigma$ deviation for three measured profiles. Model predictions are compared for $800 \mathrm{MPa}$ (short dashed line), $900 \mathrm{MPa}$ (solid line), and $1000 \mathrm{MPa}$ (long dashed line) tested for one cycle. Model results predict the surface and maximum compression fairly well while under predicting the tensile stress seen at $0.20 \mathrm{~mm}$. Model predictions for $800 \mathrm{MPa}, 900 \mathrm{MPa}$, and $1000 \mathrm{MPa}$ loaded for one cycle show that the model correctly captures the increased relaxation trend when stress is increased. Additionally, the model predicts little difference between 800 $\mathrm{MPa}$ and $900 \mathrm{MPa}$ but measurable relaxation for $1000 \mathrm{MPa}$. All of the predictions for one cycle loading at the selected stress levels retain some amount of compressive surface residual stress.

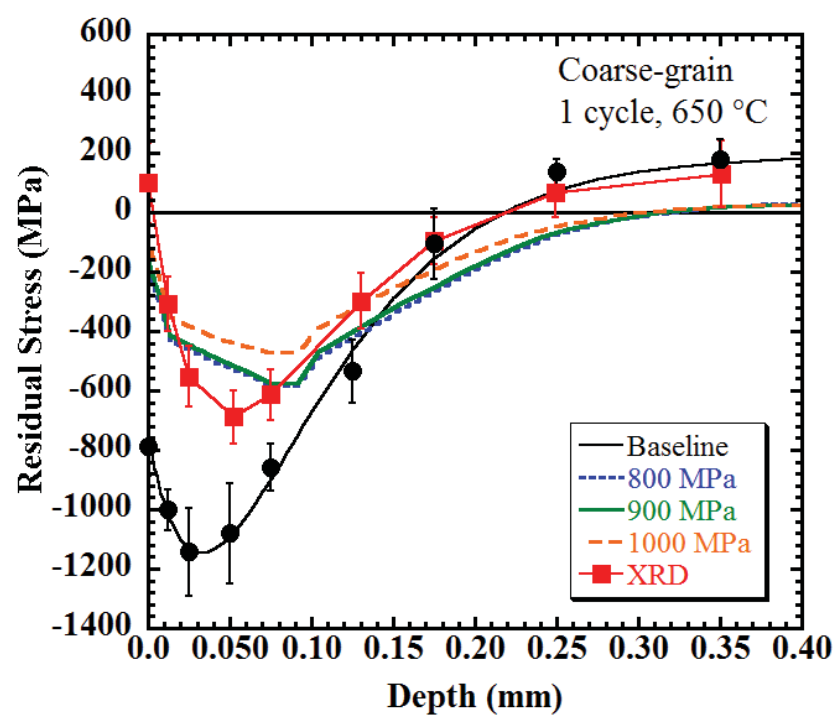

Figure 9. Residual stress versus depth from shot peened surface curves at $900 \mathrm{MPa}, 650^{\circ} \mathrm{C}$, and 1 loading cycle. Baseline, residual stress after thermomechanical exposure, and coupled creep-plasticity model incorporating microstructure predictions compared. Predictions for surrounding stress levels included for 1 cycle.

Figure 10 depicts results from subjecting the coarse-grain material to $100 \mathrm{hrs}$ of creep loading at $900 \mathrm{MPa}$ and $650{ }^{\circ} \mathrm{C}$. Symbols for Figure 10 remain the same as Figure 9 with the addition of triangle data points representing the Prism hole drilling measurements. Two holes were drilled on the same specimen face to determine the repeatability of the measurement. The Prism measurement appears to align well with the XRD measurement and confirms that at this testing condition, the residual stress becomes tensile at the surface. The tensile stress observed at the surface is the result of the load equilibrium from the compressive interior due to gross plastic deformation over the entire cross section of the specimen and is a factor of the geometry. Similar sign reversals of surface residual stresses were reported by Buchanan et al. [30] for coarse-grain IN100 and by Kirk [31] for pure nickel and copper. The model predicts the flip in the nearsurface residual stress profile from compressive to tensile and appears to be more accurate at capturing the magnitude of the stress than at the less severe condition.

The robustness of the model is shown in Figure 11 where the model is exercised at $650{ }^{\circ} \mathrm{C}$ and $900 \mathrm{MPa}$ loading stress for different mechanical loading and exposure lengths. The least amount of residual stress relaxation is shown for testing at one cycle which has the least amount of time spent at maximum load and the least exposure at temperature. 600 fatigue cycles and 0.5 $\mathrm{hr}$ creep loading are exposed for the same length of time, but the 600 cycles experience the maximum load less than the creep 
loading. Thus, the creep experiment is more detrimental to compressive stress retention than the cyclic loading. The compressive residual stress becomes tensile at the five hour exposure to load and continues to become increasingly more tensile as shown by the 100 hour exposure.

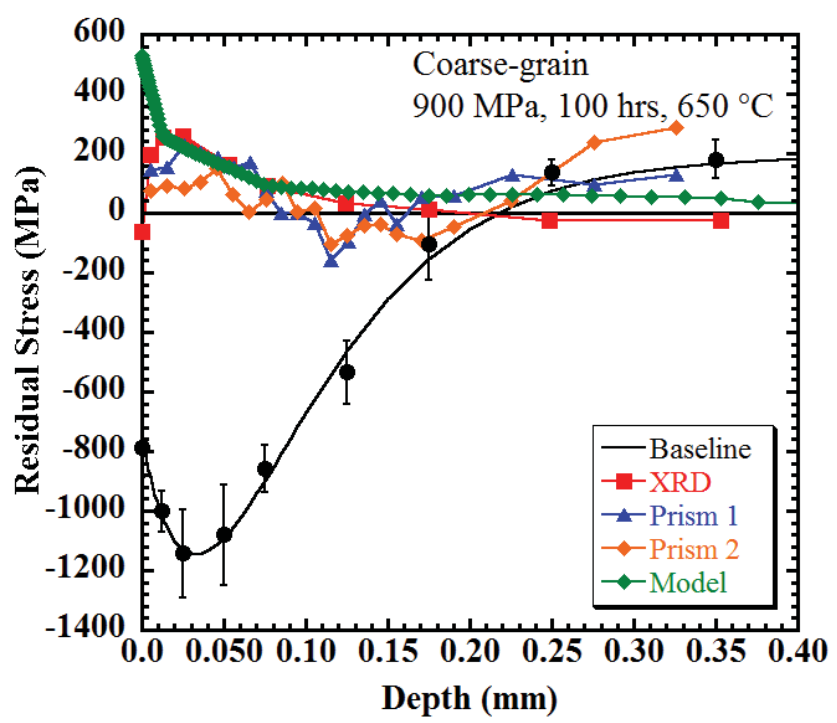

Figure 10. Residual stress versus depth from shot peened surface curves at $900 \mathrm{MPa}, 650{ }^{\circ} \mathrm{C}$, and $100 \mathrm{hrs}$ creep. Baseline, residual stress after thermomechanical exposure, and coupled creepplasticity model incorporating microstructure predictions compared.

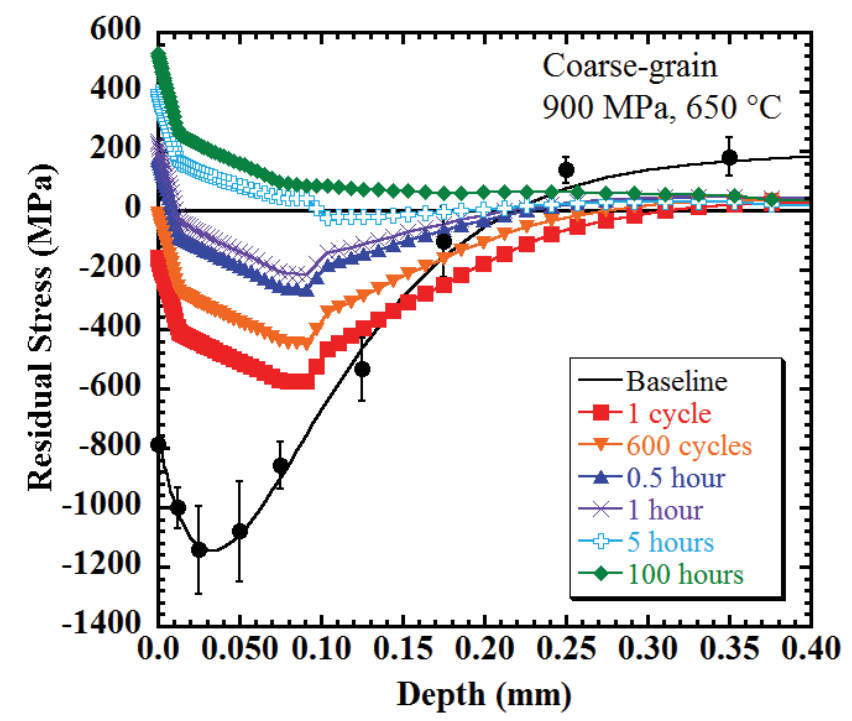

Figure $11.900 \mathrm{MPa}$ at $650{ }^{\circ} \mathrm{C}$ model predictions for different loading conditions and exposure lengths.

Similar analysis for the fine-grain material is currently in progress. Additional fatigue and creep loading experiments around the yield strength of the material have been conducted. Residual stress measurements using XRD and Prism are currently in process along with fully characterizing the baseline input profile for the finite element model. Results will be shown in future publications and a doctoral dissertation.

\section{Conclusions}

Two heat treatments (fine- and coarse-grain) of IN100 have been characterized to include subgrain $\gamma^{\prime}$ precipitates. Microstructural properties and $\gamma^{\prime}$ precipitate quantification data were implemented into a prior developed coupled creep-plasticity model with modifications to include more physics based parameters to predict surface residual stress relaxation for shot peened material. An extensive experimental study was performed to characterize the residual stress profiles by performing a round robin study on input parameters for XRD measurements, employing multiple XRD vendors to perform measurements, and capturing results from a novel surface residual stress measurement technique. Model predictions for selected thermomechanical exposure conditions capture the residual stress relaxation and redistribution trend including when the residual stress profile goes from compressive to tensile.

\section{Acknowledgements}

Research was conducted at the Air Force Research Laboratory, Materials and Manufacturing Directorate (AFRL/RXCM), Wright-Patterson Air Force Base, OH 45433-7817. This research is supporting the Materials \& Manufacturing Directorate's program on Incorporation of Residual Stresses into the Design of Ni-Base Superalloy Structures, A Foundational Engineering Problem (FEP) in Integrated Computational Materials Engineering (ICME). The authors gratefully acknowledge the experimental support of Philip Blosser.

\section{References}

1. R.C. McClung, "A literature survey on the stability and significance of residual stress during fatigue," Fatigue and Fracture of Engineering Materials and Structures, 30 (2007), 173-205.

2. D.J. Buchanan, R. John, and R.A. Brockman, "A Coupled Creep Plasticity Model for Residual Stress Relaxation of a Shot Peened Nickel-Base Superalloy," Superalloys 2008, ed. R.C. Reed, K.A. Green, P. Caron, T.P. Gabb, M.G. Fahrmann, E.S. Huron and S.A. Woodard (Warrendale, PA The Minerals, Metals, \& Materials Society, 2008), 965-974.

3. D.J. Buchanan et al., "A Coupled Creep Plasticity Model for Residual Stress Relaxation of a Shot-peened Nickel-based Superalloy," JOM, 62 (2010), 75-79.

4. D.J. Buchanan, R. John, and N.E. Ashbaugh, "Thermal Residual Stress Relaxation in Powder Metal IN100 Superalloy," Journal of ASTM International, 3 (5) (2006), 111.

5. D.J. Buchanan and R. John, "Relaxation of shot-peened residual stress under creep loading," Scripta Materialia, 59 (2009), 286-289.

6. R. John et al., "Stability of shot-peen residual stresses in an $\alpha$ + $\beta$ titanium alloy," Scripta Materialia, 61 (2009), 343-346.

7. D.J. Buchanan, R. John, and R.A. Brockman, "Relaxation of Shot-Peened Residual Stresses Under Creep Loading," 
Journal of Engineering Materials and Technology, 131 (2009), 1-10.

8. W. Cao et al., "Thermomechanical relaxation of residual stress in shot peened nickel base superalloy," Materials Science and Technology, 10 (1994), 947-954.

9. M. Khadhraoui et al., "Experimental investigations and modelling of relaxation behavior of shot peening residual stresses at high temperature for nickel base superalloys," Materials Science and Technology, 13 (1997), 360-367.

10. J. Hoffmeister et al., "Thermal Relaxation of Residual Stresses induced by Shot Peeneing in IN718," Proceedings of the $10^{\text {th }}$ International Conference for Shot Peening, ed. K. Tosha (Tokyo, Japan: Academy Common Meiji University, 2008).

11. M. Huang, Y.K. Potdar, and S. Akkaram, "Analytical Model to Predict Thermomechanical Relaxation of Shot Peening Induced Residual Stresses," Journal of Engineering for Gas Turbines and Power, 132 (2010), 1-5.

12. Matthew J. Donachie and Stephen J. Donachie, Superalloys: A Technical Guide (Materials Park, OH: ASM International, 2002), 31.

13. ASTM Standard E2627, 2013, "Standard Practice for Determining Average Grain Size Using Electron Backscatter Diffraction (EBSD) in Fully Recrystallized Polycrystalline Materials," (West Conshohocken, PA: ASTM International 2013), www.astm.org

14. V. Siva Kumar G. Kelekanjeri and R.A. Gerhardt, "Etch pit and $\gamma^{\prime}$ precipitate evolution in controlled Waspaloy microstructures aged at 725,800 and $875^{\circ} \mathrm{C}, "$ Acta Materialia, 57 (2009) 616-627.

15. A.M. Wusatowska-Sarnek et al., "Characterization of the microstructure and phase equilibria calculations for the powder metallurgy superalloy IN100," Journal of Materials Research, 18 (11) (2003), 2653-2663.

16. W.W. Milligan et al., "Effects of Microstructure on the High Temperature Constitutive Behavior of IN100," Superalloys 2004, ed. K.A. Green, T.M. Pollock, H. Harada, T.E. Howson, R.C. Reed, J.J. Schirra and S. Walston (Warrendale, PA: The Minerals, Metals, \& Materials Society, 2004), 331-339.

17. M.J. Caton et al., "Divergence of Mechanisms and the Effects on the Fatigue Life Variability of Renè 88 DT," Superalloys 2004, ed. K.A. Green, T.M. Pollock, H. Harada, T.E. Howson, R.C. Reed, J.J. Schirra and S. Walston (Warrendale, PA: The Minerals, Metals, \& Materials Society, 2004), 305-312.

18. R.W. Kozar et al., "Strengthing Mechanisms in Polycrystalline Multimodal Nickel-Base Superalloys," Metallurgical and Materials Transactions A, 40 (2009), 1588-1603.
19. T.P. Gabb et al., "Thermal and Mechanical Property Characterization of the Advanced Disk Alloy LSHR," (Report NASA/TM-2005-213645, NASA, 2005).

20. B.F. Dyson, "Microstructure based creep constitutive model for precipitation strengthened alloys: theory and application," Materials Science and Technology, 25 (2009), 213-220.

21. S.K. Sondhi, B.F. Dyson and M. McLean, "Tensioncompression creep asymmetry in a turbine disc superalloy: roles of internal stress and thermal aging," Acta Materialia, 52 (2004), 1761-1772.

22. H.C. Basoalto et al., "A Generic Microstructure-Explicit Model of Creep in Nickel-base Superalloys," Superalloys 2004, ed. K.A. Green, T.M. Pollock, H. Harada, T.E. Howson, R.C. Reed, J.J. Schirra and S. Walston (Warrendale, PA: The Minerals, Metals, \& Materials Society, 2004), 897-906.

23. H.C. Basoalto, J.W. Brooks and I. Di Martino, "Multiscale microstructure modelling for nickel based superalloys," Materials Science and Technology, 25 (2009), 221-227.

24. J. Coakley, D. Dye and H. Basoalto, "Creep and creep modelling of a multimodal nickel-base superalloy," Acta Materialia, 59 (2011), 854-863.

25. P.S. Prevéy, "X-ray Diffraction Characterization of Residual Stresses Produced by Shot Peening," Shot Peening Theory and Application, ed. A. Niku-Lari, (Gournay-Sur-Marne, France: IITT-International, 1990), 81-93.

26. ASTM Standard E1426, 2014, "Standard Test Method for Determining the X-Ray Elastic Constants for Use in the Measurement of Residual Stress Using X-Ray Diffraction Techniques," (West Conshohocken, PA: ASTM International 2014), www.astm.org

27. G.S. Schajer and M. Steinzig, "Full-field Calculation of Hole Drilling Residual Stress from Electronic Speckle Pattern Interferometry Data," Experimental Mechanics, 45 (6) (2005), 526-532.

28. G.S. Schajer and T.J. Rickert, "Incremental Computations Technique for Residual Stress Calculations Using the Integral Method," Experimental Mechanics, 51 (2011) 1217 1222.

29. C. Timbrell and R. Chandwani, Zentech, UK, (www.zentech.co.uk).

30. D.J. Buchanan and R. John, "Residual Stress Redistribution in Shot Peened Samples Subject to Mechanical Loading," Materials Science \& Engineering A, 615 (2014), 70-78.

31. D. Kirk, "Effects of Plastic Straining on Residual Stresses Induced by Shot-Peening," Proceedings of the Third International Conference on Shot Peening, ed. H. Wohlfahrt, R. Kopp and O. Vöhringer (Garmisch-Partenkirchen, Germany: 1987), 213-220. 